\title{
Do the correlates of screen time and sedentary time differ in preschool children?
}

\author{
Katherine L Downing ${ }^{1 *}$, Trina Hinkley', Jo Salmon ${ }^{1}$, Jill A Hnatiuk ${ }^{2}$ and Kylie D Hesketh ${ }^{1}$
}

\begin{abstract}
Background: Preschool children can spend up to $12 \mathrm{~h}$ a day in sedentary time and few meet current recommendations for screen time. Little is known about ecological correlates that could be targeted to decrease specific versus total sedentary behaviour. This study examined whether the correlates of screen time and sedentary time differ in preschool boys and girls.

Methods: Parents participating in the HAPPY Study in 2008/09 in Melbourne, Australia reported their child's usual screen time and potential individual, social and physical environment correlates. Children wore ActiGraph GT1M accelerometers for eight days to objectively assess sedentary time $\left(<100\right.$ counts. $\left.\mathrm{min}^{-1}\right)$. Multivariable linear regression analyses were performed, stratified by sex and controlling for child age, preschool/childcare attendance and clustering by centre of recruitment. Correlates significantly associated with screen time or sedentary time in individual models $(p<0.05)$ were included in final combined models.
\end{abstract}

Results: Children were sedentary for 301.1 (SD 34.1) minutes/day and spent 108.5 (SD 69.6) minutes/day in screen time. There were no sex differences in screen or sedentary time. In the final models, sleep duration was inversely associated with girls' sedentary time and boys' screen time. The only other consistent correlates for boys and girls were parental self-efficacy to limit screen time and screen time rules, which were inversely associated with screen time for both sexes. Parents reporting that they get bored watching their child play was inversely associated and maternal television viewing was positively associated with boys' screen time. Paternal age was positively associated with boys' sedentary time. Maternal ethnicity was inversely associated and paternal education, child preferences for sedentary behaviour, and parental concerns about child's physical activity and sedentary behaviour were positively associated with girls' screen time.

Conclusions: The modifiable correlates of total sedentary and screen time identified in this study could be targeted in interventions to reduce these behaviours. With correlates differing for screen and sedentary time, and between boys and girls, interventions may also benefit from including behaviour- and sex-specific strategies.

Keywords: Sedentary behaviour, Sedentary time, Screen time, Preschool children, Paediatric, Accelerometry, Television viewing

\section{Background}

Sedentary behaviour, defined as any seated, waking behaviours requiring $\leq 1.5$ Metabolic Equivalent of Tasks (METs) to perform [1], can include watching television, playing electronic games and reading. Sedentary behaviour research to date has generally focused on screen time (i.e., the sum of time spent viewing television, playing electronic games, and using a computer or other electronic devices) and, to a

\footnotetext{
* Correspondence: k.downing@deakin.edu.au

${ }^{1}$ Institute for Physical Activity and Nutrition (IPAN), School of Exercise and

Nutrition Sciences, Deakin University, Geelong, Australia

Full list of author information is available at the end of the article
}

lesser extent, sedentary time (objectively assessed, e.g., by accelerometry). Sedentary behaviours have their genesis in early childhood (birth through 5 years of age) [2]. While there is currently no evidence for negative health consequences of sedentary time in early childhood [3], excessive screen time has been associated with poorer cognitive development and well-being, and increased risk of overweight and obesity [4-6].

A recent systematic review found that preschool children (roughly 3 to 5 years) spend up to $12 \mathrm{~h}$ per day in total (objectively measured) sedentary time [7]. 
Additionally, research suggests that preschool children spend an average of two hours per day engaging in screen time [8-11], with approximately one quarter meeting current recommendations of less than one hour of screen time per day $[8,9,12]$. Given the low level of compliance with screen time recommendations and high levels of sedentary time, it is important to identify the factors that are associated with specific and sedentary time in young children in order to inform the development of appropriate intervention strategies.

A systematic review of correlates of sedentary behaviour in preschool children found that studies investigating potential correlates of sedentary behaviour have largely examined television viewing only, with very few investigating correlates of overall screen time or sedentary time [13]. That review also found few consistent correlates of screen and sedentary time. A more recent review examining correlates of energy balance-related behaviours in preschool children found that parental body mass index (BMI), family size, higher energy intake, consumption of high energy drinks, consumption of savoury snacks, parental television viewing time, the presence of a television in the bedroom, having a cable subscription and the day of the week (weekdays) were positively associated with screen time, while fruit consumption and living in an urban region were inversely associated with screen time, with no differences in correlates between sexes reported [14]. However, that review focused exclusively on screen time, with correlates of sedentary time not reported. Studies investigating sedentary time in preschool children have reported that girls are significantly more sedentary than boys $[15,16]$. Further, television/video games and physical activity equipment in the home were also shown to be positively associated with sedentary time for boys, while child BMI z-scores and parent-reported athletic coordination were significantly associated with sedentary time for girls [15].

No studies have been identified that examine the correlates of screen time and sedentary time in preschool children in the same sample; however, recent research of this nature in 9- to 11-year-old children has shown that the correlates of these behaviours differ $[17,18]$. This suggests that there is a need to investigate screen time and sedentary time as separate behaviours, potentially requiring different strategies to decrease time in those behaviours. Moreover, research has shown that correlates of sedentary behaviours differ between the sexes in preschool [15, 19] and school-aged [17, 18] children, suggesting that correlates should be investigated separately for boys and girls. The aim of this study was to investigate whether the correlates of screen time and sedentary time differ in 3- to 5-year-old boys and girls.

\section{Methods}

\section{Recruitment and participants}

This study used baseline data (from 2008/09) drawn from the Healthy Active Preschool and Primary Years (HAPPY) Study when children were 3 to 5 years old. HAPPY is a cohort study, conducted in Melbourne, Australia, that investigates multi-domain correlates of physical activity and sedentary behaviour. Recruitment and data collection for this study have previously been described [20]. Briefly, two local government areas (LGAs) within each of the lowest, middle and highest socioeconomic quintiles in metropolitan Melbourne were randomly selected (six in total). Within each of those LGAs, once permission was granted, 124 preschools and 146 childcare centres were randomly selected and invited to participate. All parents $(n=9794)$ of children aged 3 to 5 years at consenting preschools and childcare centres were then invited to participate in the study. Data were collected from 1002 children and their parents (11\% response rate). The final sample included 937 children ( $n=504$ boys) with valid screen time data and 724 children ( $n=397$ boys) with valid accelerometry data. The Deakin University Human Research Ethics Committee and the Department of Education and Early Childhood Development approved the study.

\section{Measures and data management Outcome variables}

Children were fitted with ActiGraph GT1M uniaxial accelerometers (Pensacola, FL, USA) on an elastic belt at the right iliac crest and instructed to wear them during waking hours for 8 consecutive days to objectively assess sedentary time. ActiGraph accelerometers have established validity and reliability in preschool-aged children [21]. Data were collected in 15-s epochs [22, 23] to account for the sporadic nature of young children's physical activity. Non-wear time was determined as $\geq 10$ min of consecutive zero counts [24]. Sedentary time was classified using Evenson et al. [25] cut points of $\leq 25$ counts per 15-s epoch. To be included in the analyses, children were required to have data recorded for at least $6 \mathrm{~h}$ per day on at least 4 days (including at least 1 weekend day) [24]. To account for variations in children's accelerometer wear time, sedentary time was standardized using the residuals obtained when regressing sedentary time on wear time [26].

During the week that children wore the accelerometer, parents completed surveys reporting their child's usual television/video/DVD time, computer use, and sedentary electronic game use (in hours and minutes) on weekdays (i.e., total time from Monday to Friday) and on weekend days (i.e., total time on Saturday and Sunday). Responses were converted to minutes, then weekday and weekend 
responses were summed and divided by seven to give average daily minutes of screen time.

\section{Explanatory variables}

Explanatory variables in this study were derived from three levels of the ecological model (individual, social and physical environment) [27]. Children's height $(\mathrm{m})$ and weight $(\mathrm{kg})$ were measured using standardized measurement procedures by trained researchers with a Wedderburn Seca portable rigid stadiometer and Wedderburn Tanita portable digital scales respectively [28, 29]. Parents self-reported their height and weight and that of their partner (where applicable); BMI was calculated $\left(\mathrm{kg} / \mathrm{m}^{2}\right)$ for children and parents. Child BMI categories were determined using ageand sex-specific international cut-off points $[30,31]$ and WHO classifications [32] were used for parents.

Parents reported individual domain correlates $(n=29)$ including biological and demographic variables (e.g., parent's age, country of birth, education; child's sleep duration, number of siblings); child behavioural variables (e.g., participation in organized activities, outdoor play time); and psychological variables (e.g., child preferences for physical activity and screen time). Social domain correlates $(n=26)$ included parental variables (e.g., parental constraints to supporting physical activity, parental rules and regulations regarding physical activity and screen time) and broader social variables (e.g., role-modelling of physical activity and screen time, social gatherings). Physical environment domain correlates $(n=12)$ included home environment variables (e.g., number of televisions in the home, indoor play spaces), and broader neighbourhood variables (e.g., park and playground availability and quality, frequency of visits to active play spaces). Only survey items with established test-retest reliability were included in analyses: for categorical items Kappa $>0.60$ and/ or per cent agreement $>60 \%$; and for continuous variables ICC $>0.50$ [33]. See (Additional file 1: Table S1) for a full list of potential correlates included in analyses.

\section{Data analysis}

Analyses were performed in Stata 13.0 (StataCorp, Texas, USA). Descriptive statistics were used to characterize the sample and t-tests were used to determine differences in sedentary and screen time between boys and girls. Multivariable linear regression models were used to identify correlates of sedentary time and screen time. Initially, each potential correlate was included in individual models with each of the two outcomes. Variables that were significant in individual models $(p<0.05)$ were included in combined models. Collinearity of variables included in the combined models was tested using tolerance and variance inflation factors (VIFs); no issues with collinearity were identified. Given that child age was positively associated with sedentary time for both boys $(\beta=8.33,95 \%$ CI 4.46 , $12.20)$ and girls ( $\beta=7.93,95 \%$ CI $2.78,13.07)$, all models controlled for child age. Additionally, given that in Australian children have varying preschool/childcare hours, all models controlled for hours of preschool/ childcare attendance per week. Models also controlled for clustering by centre of recruitment and were performed separately by child sex.

\section{Results}

Descriptive data have previously been reported $[8,20]$. Respondent parents (93.7\% female) had a mean (SD) age of 37.3 (5.2) years and $69.8 \%$ were born in Australia. Children had a mean (SD) age of 4.5 (0.7) years. Boys spent a mean (SD) of 109.8 (69.8) minutes per day and girls spent a mean (SD) of 107.0 (69.4) minutes per day in screen time $(p>0.05)$. Accelerometry data showed that boys were sedentary for a mean (SD) of 303.0 (34.6) minutes per day while girls spent a mean (SD) of 298.8 (33.4) minutes per day sedentary $(p>0.05)$.

Table 1 shows individual model results for screen and sedentary time, stratified by child sex. Individual models showed that 22 variables (six, 11 and five from the individual, social and physical environment domains, respectively) were significantly associated with boys' screen time, while 28 variables $(10,12$ and six from the individual, social and physical environment domains, respectively) were significantly associated with girls' screen time. For sedentary time, five potential correlates (two, one and two from the individual, social and physical environment domains, respectively) were identified in the individual models for boys and five (four, zero and one from the individual, social and physical environment domains, respectively) were identified for girls.

Table 2 presents the results of the combined models for correlates of screen and sedentary time, stratified by child sex. In the combined model, for boys, five correlates remained significantly associated with screen time and one correlate remained significantly associated with sedentary time. For girls, seven correlates remained significantly associated with screen time and one variable remained significantly associated with sedentary time. No common correlates of screen and sedentary time were identified for either boys or girls.

In the combined model, for each additional hour of sleep, boys spent $7.5 \mathrm{~min}$ less per day in screen time. For every unit increase in parental self-efficacy to limit screen time and their actual rules to limit screen time, boys spent $6.5 \mathrm{~min}$ and $5.2 \mathrm{~min}$ less per day in screen time, respectively. If parents reported that they get bored watching their child play, boys spent 14.4 min less per day in screen time. Conversely, maternal television viewing was positively associated with boys' screen time, such 


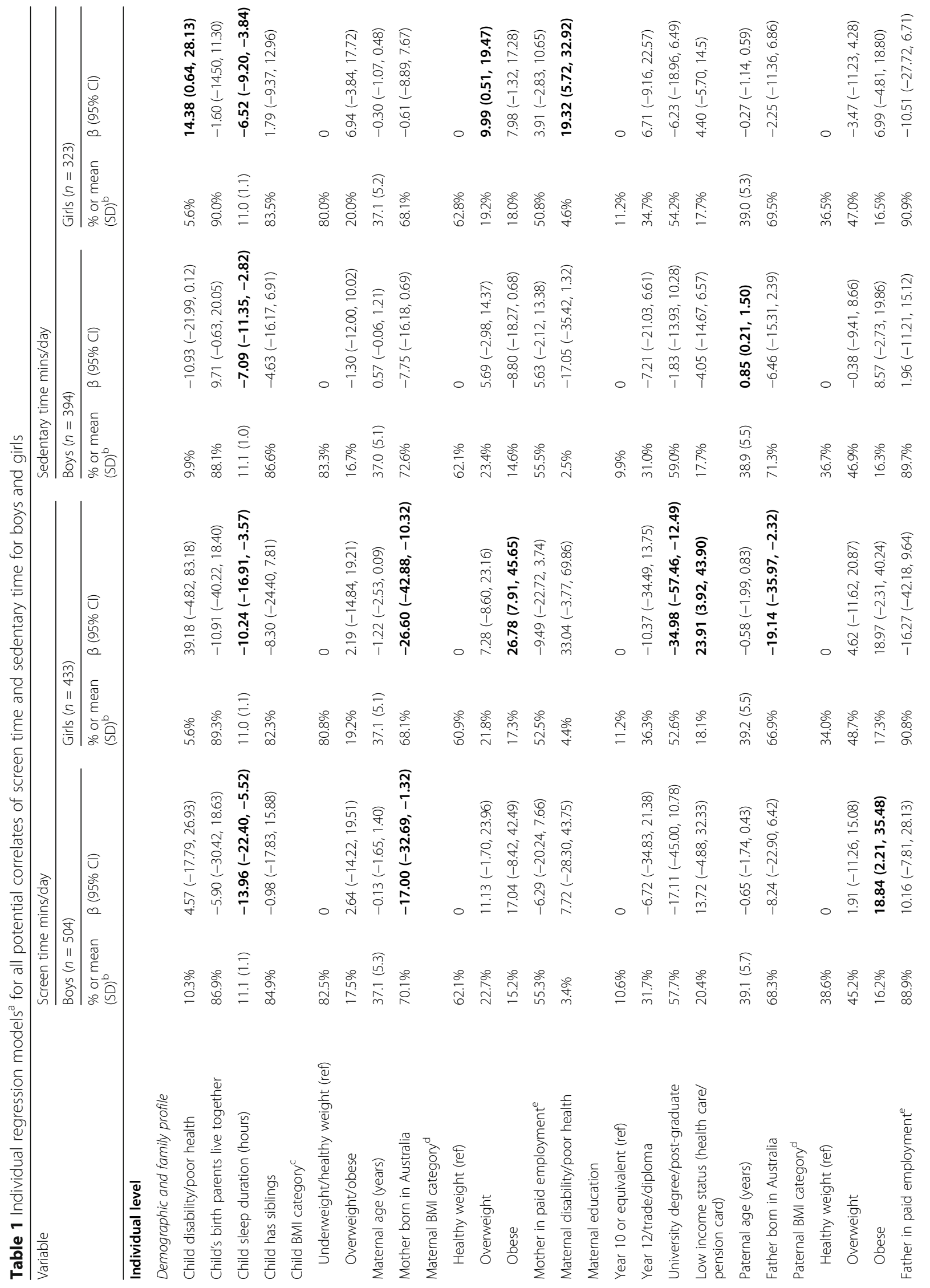




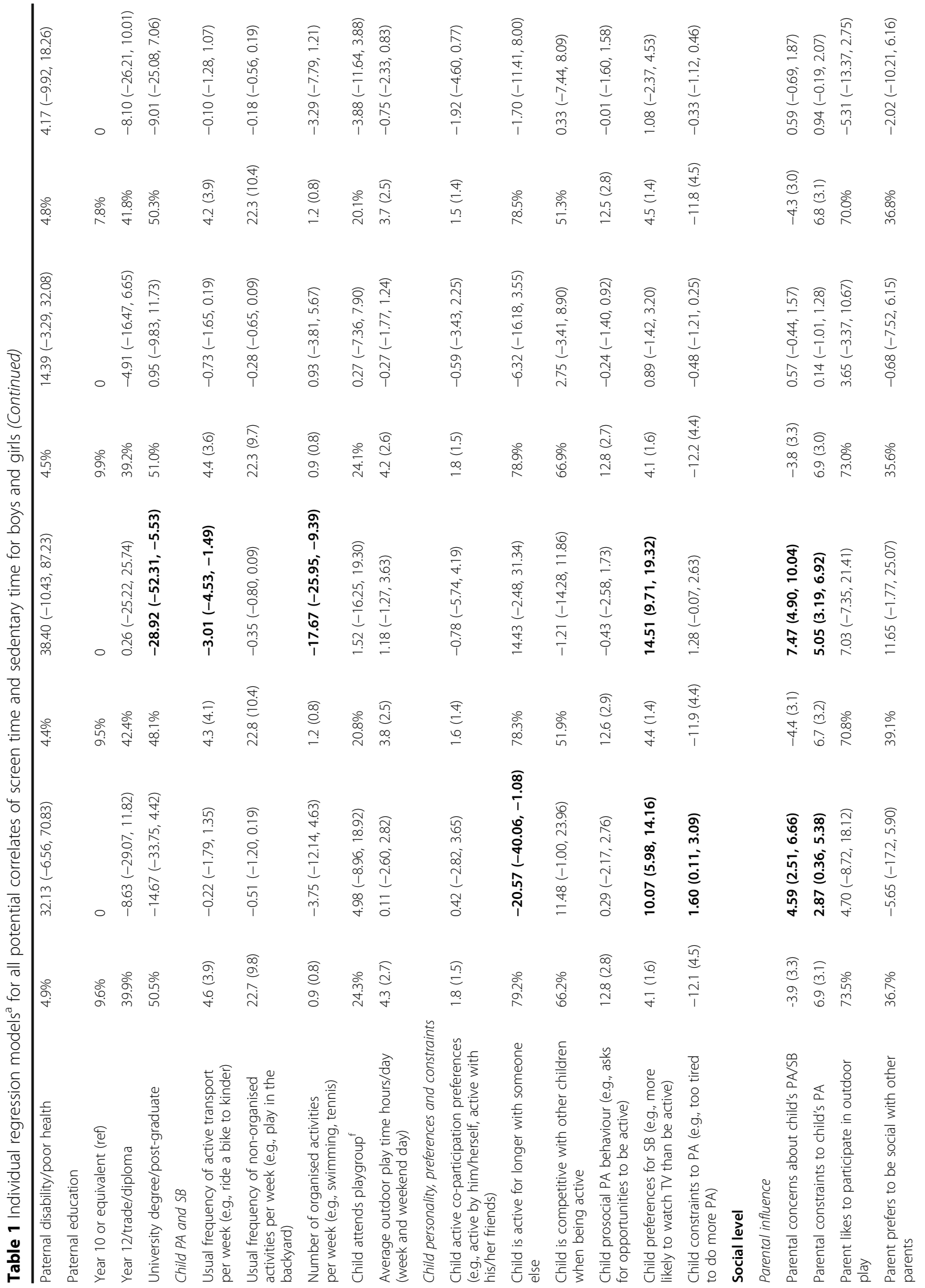




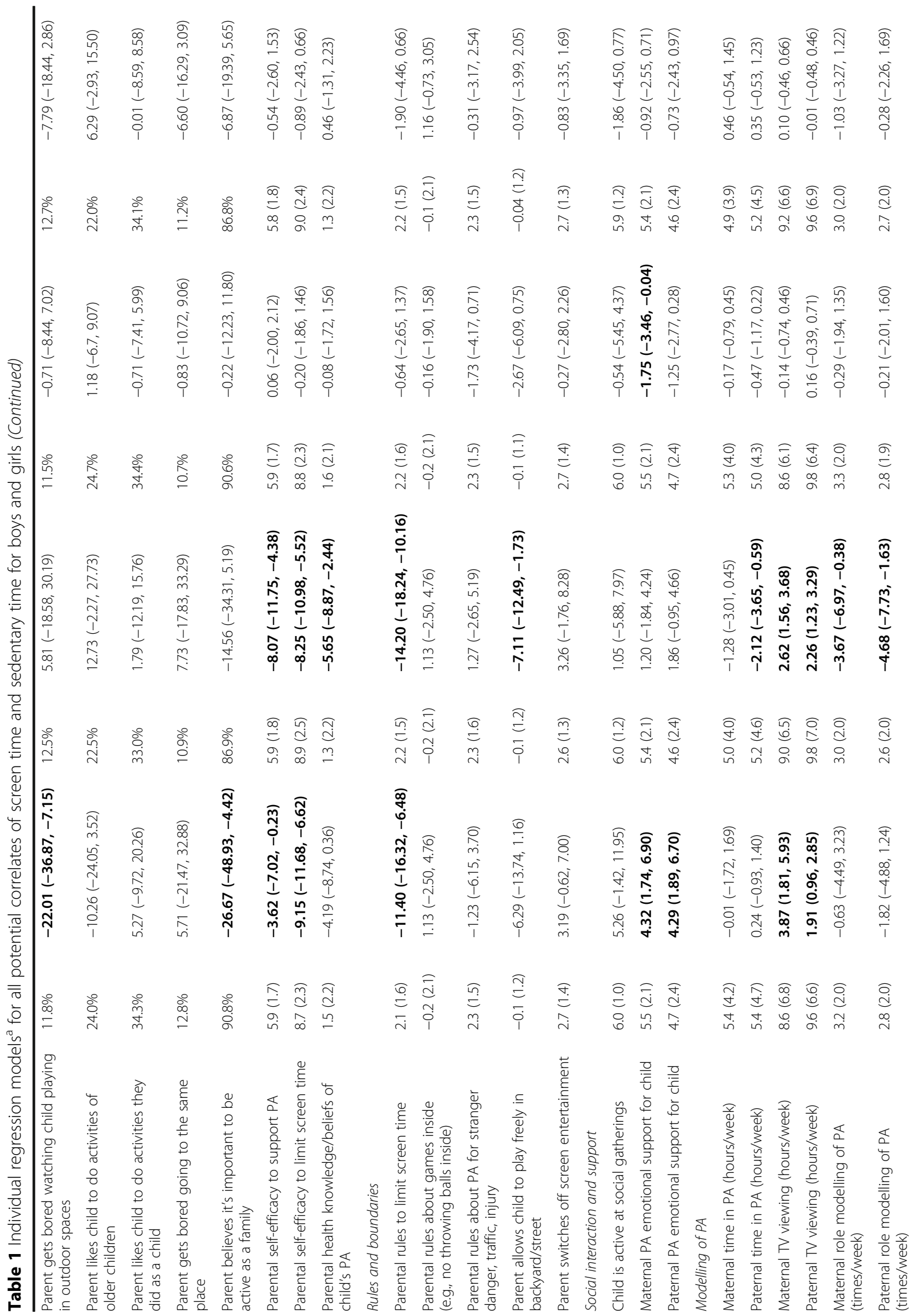




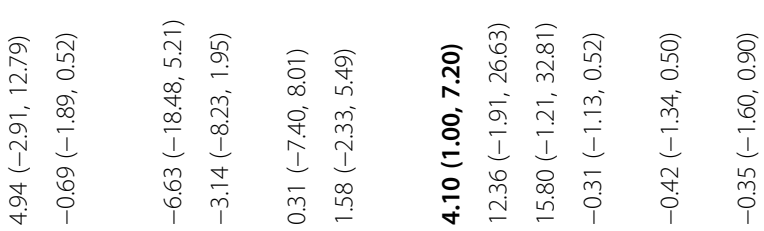

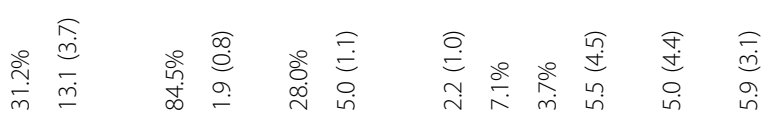

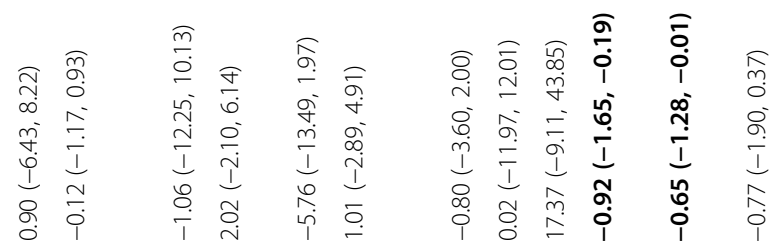

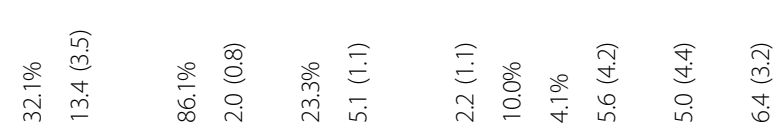

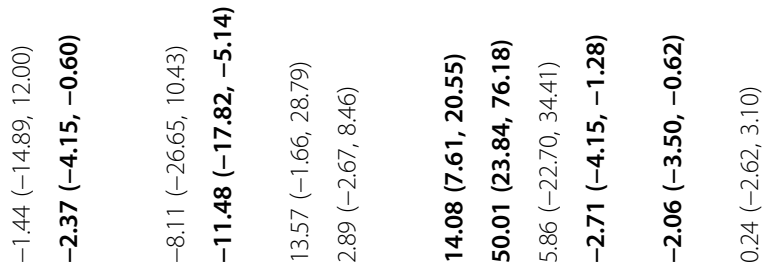

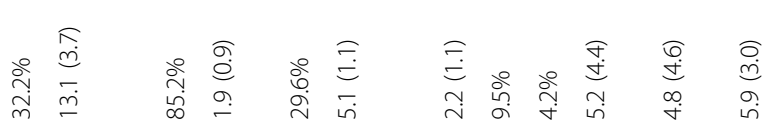

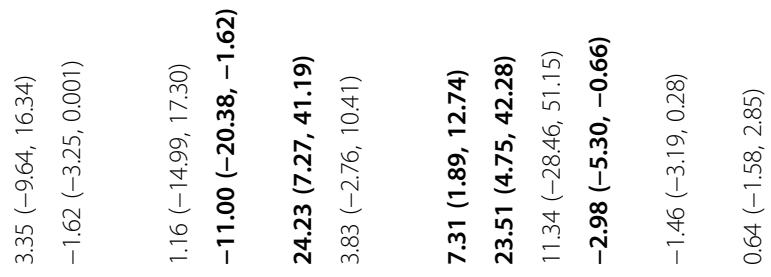

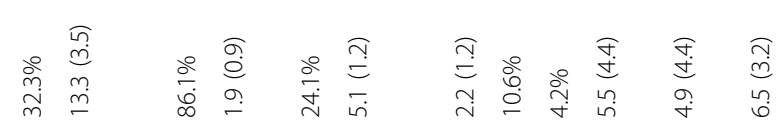

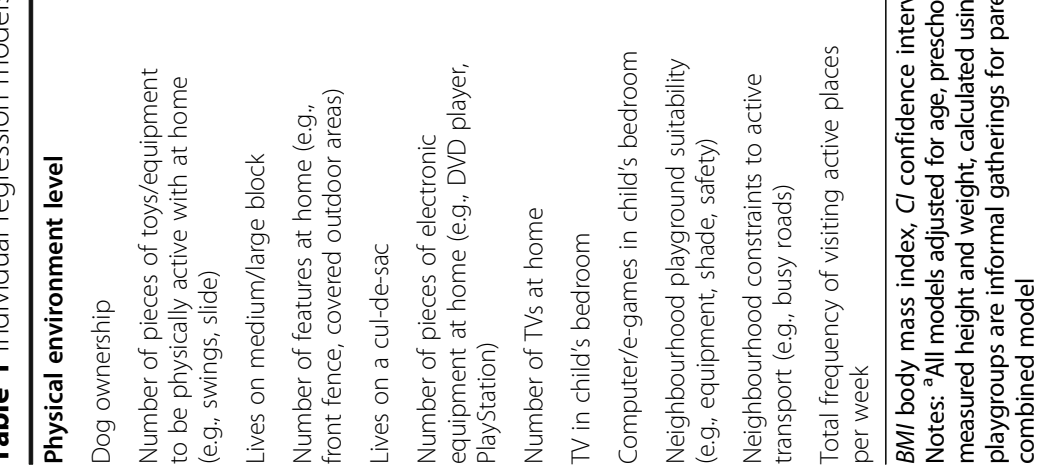


Table 2 Combined regression models ${ }^{a}$ for correlates of screen time and sedentary time for boys and girls

\begin{tabular}{|c|c|c|c|c|}
\hline \multirow[t]{3}{*}{ Variable } & \multicolumn{2}{|l|}{ Screen time mins/day } & \multicolumn{2}{|c|}{ Sedentary time mins/day } \\
\hline & Boys $(n=504)$ & Girls $(n=433)$ & Boys $(n=394)$ & Girls $(n=323)$ \\
\hline & $\beta(95 \% \mathrm{Cl})$ & $\beta(95 \% \mathrm{Cl})$ & $\beta(95 \% \mathrm{Cl})$ & $\beta(95 \% \mathrm{Cl})$ \\
\hline \multicolumn{5}{|l|}{ Individual level } \\
\hline \multicolumn{5}{|l|}{ Demographic and family profile } \\
\hline Child disability/poor health & - & - & - & $10.18(-3.03,23.40)$ \\
\hline Child sleep duration (hours) & $-7.49(-13.46,-1.52)$ & $-5.67(-11.57,0.23)$ & $-3.97(-7.95,0.01)$ & $-5.76(-8.83,-2.69)$ \\
\hline Mother born in Australia & $0.99(-11.45,13.42)$ & $-15.66(-28.97,-2.35)$ & - & - \\
\hline \multicolumn{5}{|l|}{ Maternal BMI category ${ }^{c}$} \\
\hline Healthy weight (ref) & - & 0 & - & 0 \\
\hline Overweight & - & $1.56(-12.22,15.34)$ & - & $8.55(-0.90,18.00)$ \\
\hline Obese & - & $15.11(-4.11,34.32)$ & - & $5.20(-4.05,14.45)$ \\
\hline Maternal disability/poor health & - & - & - & $10.97(-5.36,27.30)$ \\
\hline \multicolumn{5}{|l|}{ Maternal education } \\
\hline Year 10 or equivalent (ref) & - & 0 & - & - \\
\hline Year 12/trade/diploma & - & $-3.39(-27.86,21.09)$ & - & - \\
\hline University degree/post-graduate & - & $-2.62(-30.91,25.66)$ & - & - \\
\hline Low income status (health care/pension card) & - & $-4.22(-23.18,14.74)$ & - & - \\
\hline Paternal age (years) & - & - & $0.73(0.10,1.35)$ & - \\
\hline Father born in Australia & - & $-3.93(-17.82,9.95)$ & - & - \\
\hline \multicolumn{5}{|l|}{ Paternal BMI category ${ }^{c}$} \\
\hline Healthy weight (ref) & 0 & - & - & - \\
\hline Overweight & $-1.15(-13.03,10.74)$ & - & - & - \\
\hline Obese & $2.79(-12.80,18.37)$ & - & - & - \\
\hline \multicolumn{5}{|l|}{ Paternal education } \\
\hline Year 10 or equivalent (ref) & - & 0 & - & - \\
\hline Year 12/trade/diploma & - & $23.26(0.11,46.41)$ & - & - \\
\hline University degree/post-graduate & - & $9.66(-16.33,35.65)$ & - & - \\
\hline \multicolumn{5}{|l|}{ Child PA and SB } \\
\hline $\begin{array}{l}\text { Usual frequency of active transport per week } \\
\text { (e.g., ride a bike to kinder) }\end{array}$ & - & $-1.72(-3.14,-0.30)$ & - & - \\
\hline $\begin{array}{l}\text { Number of organised activities per week } \\
\text { (e.g., swimming, tennis) }\end{array}$ & - & $-7.54(-15.72,0.64)$ & - & - \\
\hline \multicolumn{5}{|l|}{ Child personality, preferences and constraints } \\
\hline Child is active for longer with someone else & $-10.63(-23.18,1.93)$ & - & - & - \\
\hline $\begin{array}{l}\text { Child preferences for SB (e.g., more likely } \\
\text { to watch TV than be active) }\end{array}$ & $3.52(-1.49,8.53)$ & $7.09(2.47,11.70)$ & - & - \\
\hline $\begin{array}{l}\text { Child constraints to PA (e.g., too tired to } \\
\text { do more PA) }\end{array}$ & $-0.69(-2.12,0.75)$ & - & - & - \\
\hline \multicolumn{5}{|l|}{ Social level } \\
\hline \multicolumn{5}{|l|}{ Parental influence } \\
\hline Parental concerns about child's PA/SB & $1.87(-0.05,3.78)$ & $3.19(0.62,5.76)$ & - & - \\
\hline Parental constraints to child's PA & $0.74(-1.36,2.84)$ & $1.29(-0.55,3.13)$ & - & - \\
\hline $\begin{array}{l}\text { Parent gets bored watching child playing } \\
\text { in outdoor spaces }\end{array}$ & $-14.43(-27.99,-0.86)$ & - & - & - \\
\hline $\begin{array}{l}\text { Parent believes it's important to be } \\
\text { active as a family }\end{array}$ & $6.08(-10.86,23.02)$ & - & - & - \\
\hline
\end{tabular}


Table 2 Combined regression models ${ }^{a}$ for correlates of screen time and sedentary time for boys and girls (Continued)

\begin{tabular}{|c|c|c|c|c|}
\hline Parental self-efficacy to support PA & $0.76(-2.78,4.30)$ & $1.67(-2.23,5.58)$ & - & - \\
\hline Parental self-efficacy to limit screen time & $-6.52(-9.51,-3.54)$ & $-2.64(-5.12,-0.16)$ & - & - \\
\hline Parental health knowledge/beliefs of child's PA & - & $0.22(-3.67,4.11)$ & - & - \\
\hline \multicolumn{5}{|l|}{ Rules and boundaries } \\
\hline Parental rules to limit screen time & $-5.15(-9.20,-1.11)$ & $-5.20(-9.94,-0.47)$ & - & - \\
\hline $\begin{array}{l}\text { Parent allows child to play freely in } \\
\text { backyard/street }\end{array}$ & - & $-4.62(-9.39,0.16)$ & - & - \\
\hline \multicolumn{5}{|l|}{ Social interaction and support } \\
\hline Maternal PA emotional support for child & $2.14(-1.47,5.76)$ & - & $-1.10(-2.84,0.63)$ & - \\
\hline Paternal PA emotional support for child & $2.14(-0.87,5.14)$ & - & - & - \\
\hline \multicolumn{5}{|l|}{ Modelling of PA } \\
\hline Paternal time in PA (hours/week) & - & $-0.62(-2.29,1.04)$ & - & - \\
\hline Maternal TV viewing (hours/week) & $2.27(1.09,3.46)$ & $1.33(-0.05,2.70)$ & - & - \\
\hline Paternal TV viewing (hours/week) & $0.49(-0.71,1.69)$ & $0.65(-0.33,1.63)$ & - & - \\
\hline Maternal role modelling of PA (times/week) & - & $0.36(-3.27,4.00)$ & - & - \\
\hline Paternal role modelling of PA (times/week) & - & $0.54(-3.54,4.61)$ & - & - \\
\hline \multicolumn{5}{|l|}{ Physical environment level } \\
\hline $\begin{array}{l}\text { Number of pieces of toys/ equipment to be } \\
\text { physically active with at home (e.g., swings, slide) }\end{array}$ & - & $0.57(-1.15,2.29)$ & - & - \\
\hline $\begin{array}{l}\text { Number of features at home (e.g., front fence, } \\
\text { covered outdoor areas) }\end{array}$ & $-2.51(-9.95,4.92)$ & $-2.34(-9.40,4.72)$ & - & - \\
\hline Lives on a cul-de-sac & $11.70(-1.26,24.66)$ & - & - & - \\
\hline Number of TVs at home & $3.65(-2.04,9.34)$ & $5.15(-1.69,11.99)$ & - & $2.45(-0.79,5.70)$ \\
\hline TV in child's bedroom & $-1.74(-23.72,20.23)$ & $27.14(-5.49,59.77)$ & - & - \\
\hline $\begin{array}{l}\text { Neighbourhood playground suitability } \\
\text { (e.g., equipment, shade, safety) }\end{array}$ & $0.11(-1.10,1.32)$ & $-0.69(-2.11,0.73)$ & $-0.69(-1.51,0.12)$ & - \\
\hline $\begin{array}{l}\text { Neighbourhood constraints to active transport } \\
\text { (e.g., busy roads) }\end{array}$ & - & $0.14(-1.29,1.57)$ & $-0.26(-0.96,0.43)$ & - \\
\hline
\end{tabular}

that boys spent an additional 2.3 min per day in screen time for each additional hour in maternal television viewing. For sedentary time, boys spent an additional 0.7 min per day sedentary for every additional year of paternal age.

For girls, results from the combined model show that if mothers were born in Australia, girls spent $15.7 \mathrm{~min}$ less per day in screen time. For every unit increase in parental self-efficacy to limit screen time and rules to limit screen time, girls spent $6.5 \mathrm{~min}$ and $2.6 \mathrm{~min}$ less per day in screen time, respectively. Paternal education, child preferences for sedentary behaviour (e.g. child is more likely to watch television than be active), and parental concerns about their child's physical activity and sedentary behaviour were positively associated with girls' screen time. If fathers had a year 12/trade/diploma level of education, girls spent 23.3 min more per day in screen time compared to fathers with a year 10 or equivalent level of education. Girls also spent $7.1 \mathrm{~min}$ per day more in screen time for each unit increase in parent-reported child preferences for sedentary behaviour, and $3.1 \mathrm{~min}$ more per day in screen time for every unit increase in parental concerns about their child's physical activity and sedentary behaviour. For sedentary time, girls spent $5.8 \mathrm{~min}$ less per day sedentary for every additional hour of sleep time.

\section{Discussion}

The aim of this study was to identify whether correlates of screen time and sedentary time in preschool children differ. Results identified a greater number of correlates of screen time than sedentary time in this population. No common correlates of screen and sedentary time were identified for either boys or girls. The larger number of correlates of screen time than sedentary time is consistent with research in older 
children [17, 18]. This may be because in this study both screen time and potential correlates were parent-reported, whereas sedentary time was objectively measured, hence there may have been consistent reporting biases that influenced associations for screen time. Additionally, many of the correlates measured focus directly on screen time (e.g., parents limiting screen time) rather than sedentary time (e.g., strategies to reduce overall sitting). They may therefore be less relevant to sedentary time which, when measured by accelerometry, captures many more types of sedentary behaviour in addition to screens (e.g., reading, craft, quiet play) across many domains (e.g., in the car, at preschool, in the home). Most research to date has focused only on screen time [14], which is often used as a proxy for sedentary time [34]. However, results from the current study suggest that the correlates of these behaviours differ, and therefore behaviour-specific strategies may be required to reduce screen time and sedentary time.

Children's total sleep time (including daytime naps) was significantly inversely associated with girls' sedentary time and boys' screen time. The association between sedentary time and sleep has not previously been investigated in preschool children, but research in older children supports this inverse association [17]. Previous research has found that increased sleep time is associated with decreased television viewing in five-year-old children [35]. In the current study it is not possible to determine whether children are engaging in higher levels of screen time and sedentary time due to less sleep, or whether the higher levels of sedentary time and screen time disrupt sleep. However, screen time at age two years has been longitudinally inversely associated with sleep duration at age five years [36], suggesting that encouraging parents to decrease their child's screen time to improve sleep could be an appealing strategy for parents.

The only other common correlates for boys' and girls' screen time were parental self-efficacy to limit screen time and their actual rules to limit screen time. For every unit increase in the summed score for parental self-efficacy to limit screen time, boys and girls spent around six and three minutes less per day in screen time, respectively. Similarly, for every unit increase in parental rules, boys and girls both spent around five minutes less per day in screen time. Parental self-efficacy to limit screen time and their actual rules have consistently been shown to be inversely associated with screen time in preschool children [37-43]. This suggests that interventions and public health strategies to reduce sedentary behaviour could potentially give parents strategies to implement screen time rules, and in turn increase parental self-efficacy to limit screen time.
Consistent with research in school-aged children [17], there were a higher number of parent demographic correlates of girls' compared to boys' screen time: maternal ethnicity and paternal education were both associated with girls' screen time, while there were no parent demographic correlates associated with boys' screen time. Conversely, there were a larger number of parental influences in the social level of the ecological model associated with boys' compared to girls' screen time. If parents reported that they get bored watching their child play in outdoor spaces, boys spent around 14 min less per day in screen time. It may be that these children have higher levels of physical activity (and therefore potentially lower levels of screen time) so their parents get bored watching for long periods of time.

Many of the associations identified in this study were relatively modest in magnitude e.g., a seven minutes less screen time for every additional hour of sleep. However, when considered in light of screen time recommendations for this age group (i.e., one hour or less per day), seven minutes equates to around $12 \%$ of this time. Given that there is evidence of a dose-response for increased screen time and poorer cognitive development and psychological health [4], even modest decreases in screen time may have significant health benefits in early childhood. Additionally, it is important to note that the magnitude of associations seen in the current study are the average for the sample, but across the population may be important for public health.

Consistent with previous research $[15,19]$, the current study found that the correlates of both screen time and sedentary time differ between boys and girls. These findings suggest that future research should recruit samples that are sufficiently large to ensure adequate power to stratify analyses by sex. Additionally, future interventions would benefit from using sex-specific strategies to reduce time in these behaviours. Despite these differences in correlates, results from this study show that preschool boys and girls spend similar amounts of time engaging in screen time and sedentary time. Previous reviews have consistently found that child sex is not associated with screen time in this population $[13,14,44]$. However, there is an indeterminate association between child sex and sedentary time, with some studies finding that preschool girls are more sedentary than boys $[15,45,46]$ and others finding no association [47, 48]. Given that girls are consistently shown to be more sedentary than boys in research involving school-aged children and adolescents [49], it may be that the sex-difference in sedentary time increases as children age. This suggests that girls may particularly benefit from early intervention.

There were several strengths to this study including the use of accelerometers to objectively assess sedentary 
time. Additionally, this study included a wide range of potential correlates covering multiple domains of the ecological model, with the parent survey purposedesigned to cover these domains and tested for reliability [33]. Despite the low response rate (11\%), the sample was large and recruited across low-, mid- and highsocioeconomic areas. Demographic characteristics were comparable with 2011 national census data; e.g., 70\% of parents vs $70 \%$ of adults born in Australia, $67 \%$ of parents vs $58 \%$ of adults with post-secondary qualifications [50]. However, results may be specific to suburban Melbourne and may not be generalizable to rural areas or other cities or countries. The cross-sectional design of the study prohibits inference of causality; future studies would benefit from employing a longitudinal design to determine causality.

Future work would also benefit from including sedentary behaviours beyond just screen time. Currently, very little is known about other, non-screen based sedentary behaviours that may have positive physical, mental and cognitive health effects (e.g., reading, quiet play). Having a better understanding of the factors associated with these other types of sedentary behaviour would help inform public health messages and interventions to reduce time in unfavourable sedentary behaviours. The current study does identify a number of modifiable factors that are associated with both screen time and sedentary time in preschool children. In particular, parental factors such as self-efficacy, modelling, and screen time rules could be potential targets for future interventions.

\section{Conclusions}

Contrary to public health recommendations, preschool children are spending large amounts of time engaging in screen and sedentary time. Few common correlates exist for screen time and sedentary time suggesting that different strategies to reduce screen time and sedentary time in this population are needed. Similarly, there were a number of different correlates for boys and girls, signifying that sex-specific strategies may be required to reduce sedentary behaviours. Parental correlates (such as self-efficacy and screen time rules) identified in this study are modifiable and could potentially be targeted in interventions and public health strategies to reduce sedentary behaviour in preschool children.

\section{Additional file}

Additional file 1: Table S1. Potential correlates of sedentary time and screen time included in individual models. (DOCX $22 \mathrm{~kb}$ )

\section{Abbreviations}

BMl: Body mass index; $\mathrm{Cl}$ : Confidence interval; E-games: Electronic games; HAPPY: Healthy active preschool and primary years; LGA: Local government area; MET: Metabolic equivalent of task; PA: Physical activity; SB: Sedentary behaviour; TV: Television; VIF: Variance inflation factor

\section{Acknowledgements}

Not applicable.

\section{Funding}

The HAPPY Study was funded by Deakin University. KLD is supported by a National Health and Medical Research Council Postgraduate Scholarship (GNT1092876). TH is supported by a National Health and Medical Research Council Early Career Fellowship (APP1070571). JS is supported by a National Health and Medical Research Council Principal Research Fellowship (APP1026216). KDH is supported by an Australian Research Council Future Fellowship (FT130100637) and an Honorary Heart Foundation Future Leader Fellowship (100370). Funding bodies had no role in design, collection, analysis, and interpretation of data; in the writing of the manuscript; or in the decision to submit the manuscript for publication.

\section{Availability of data and materials}

The questionnaire and datasets used and/or analysed during the current study are available from the corresponding author on reasonable request.

\section{Authors' contributions}

KLD provided substantial contributions to the intellectual content of the article in analysis and interpretation of the data, drafting and revision of the manuscript; TH, JS and $\mathrm{KDH}$ provided substantial contributions to the conception, design and implementation of the study and critically revised the article for interpretation of the data and intellectual content; JAH critically revised the article for interpretation of the data and intellectual content. All authors read and approved the final manuscript.

\section{Competing interests}

The authors declare that they have no competing interests.

Consent for publication

Not applicable.

\section{Ethics approval and consent to participate}

Ethics approval for the HAPPY Study was granted by the Deakin University Human Research Ethics Committee (EC 291-2007) and the Australian Government Department of Education and Early Childhood Development (2008/196). Participants provided written informed consent for themselves and their children to participate in the study.

\section{Publisher's Note}

Springer Nature remains neutral with regard to jurisdictional claims in published maps and institutional affiliations.

\section{Author details}

${ }^{1}$ Institute for Physical Activity and Nutrition (IPAN), School of Exercise and Nutrition Sciences, Deakin University, Geelong, Australia. ${ }^{2}$ School of Science and Health, Western Sydney University, Penrith, NSW 2751, Australia.

Received: 27 October 2016 Accepted: 21 March 2017

Published online: 29 March 2017

\section{References}

1. Sedentary Behaviour Research Network. Standardized use of the terms "sedentary" and "sedentary behaviours". Appl Physiol Nutr Metab. 2012;37:540-2.

2. Jones RA, Hinkley T, Okely AD, Salmon J. Tracking physical activity and sedentary behavior in childhood: a systematic review. Am J Prev Med. 2013:44(6):651-8

3. Cliff DP, Hesketh KD, Vella SA, Hinkley T, Tsiros MD, Ridgers ND, et al. Objectively measured sedentary behaviour and health and development in children and adolescents: systematic review and meta-analysis. Obes Rev. 2016;17(4):330-44.

4. LeBlanc AG, Spence JC, Carson V, Connor Gorber S, Dillman C, Janssen I, et al. Systematic review of sedentary behaviour and health indicators in the early years (aged 0-4 years). Appl Physiol Nutr Metab. 2012;37(4):753-72. 
5. Carson V, Kuzik N, Hunter S, Wiebe SA, Spence JC, Friedman A, et al. Systematic review of sedentary behavior and cognitive development in early childhood. Prev Med. 2015;78:115-22.

6. Hinkley T, Teychenne M, Downing KL, Ball K, Salmon J, Hesketh KD. Early childhood physical activity, sedentary behaviors and psychosocial well-being: a systematic review. Prev Med. 2014:62:182-92.

7. Hnatiuk JA, Salmon J, Hinkley T, Okely A, Trost S. A review of preschool children's physical activity and sedentary time using objective measures. Am J Prev Med. 2014;47(4):487-97.

8. Hinkley T, Salmon J, Okely AD, Crawford D, Hesketh K. Preschoolers' physical activity, screen time, and compliance with recommendations. Med Sci Sports Exerc. 2012;44(3):458-65.

9. Colley RC, Garriguet D, Adamo KB, Carson V, Janssen I, Timmons BW, et al. Physical activity and sedentary behavior during the early years in Canada: a cross-sectional study. Int J Behav Nutr Phys Act. 2013;10:54.

10. Loprinzi PD, Cardinal BJ, Kane C, Lee H, Beets MW. Association of active play-related parenting behaviors, orientations, and practices with preschool sedentary behavior. Am J Health Educ. 2014;45(4):229-38.

11. Veldhuis L, van Grieken A, Renders CM, Hirasing RA, Raat H. Parenting style, the home environment, and screen time of 5-year-old children; the 'Be active, eat right' study. PLoS One. 2014;9(2):e88486.

12. Carson V, Spence JC, Cutumisu N, Cargill L. Association between neighborhood socioeconomic status and screen time among pre-school children: a cross-sectional study. BMC Public Health. 2010;10:367.

13. Hinkley T, Salmon J, Okely AD, Trost SG. Correlates of sedentary behaviours in preschool children: a review. Int J Behav Nutr Phys Act. 2010;7:66.

14. De Craemer M, De Decker E, De Bourdeaudhuij I, Vereecken C, Deforche B, Manios $Y$, et al. Correlates of energy balance-related behaviours in preschool children: a systematic review. Obes Rev. 2012;13(Suppl 1):13-28.

15. Byun W, Dowda M, Pate RR. Correlates of objectively measured sedentary behavior in US preschool children. Pediatrics. 2011;128(5):937-45.

16. Dolinsky DH, Brouwer RJ, Evenson KR, Siega-Riz AM, Ostbye T. Correlates of sedentary time and physical activity among preschool-aged children. Prev Chronic Dis. 2011;8(6):A131.

17. LeBlanc AG, Broyles ST, Chaput JP, Leduc G, Boyer C, Borghese MM, et al. Correlates of objectively measured sedentary time and self-reported screen time in Canadian children. Int J Behav Nutr Phys Act. 2015;12:38.

18. LeBlanc AG, Katzmarzyk PT, Barreira TV, Broyles ST, Chaput JP, Church TS, et al. Correlates of Total Sedentary Time and Screen Time in 9-11 Year-Old Children around the World: The International Study of Childhood Obesity. Lifestyle and the Environment PLoS ONE. 2015;10(6):e0129622.

19. Hinkley T, Salmon J, Okely AD, Crawford D. The correlates of preschoolers' compliance with screen recommendations exist across multiple domains. Prev Med. 2013;57(3):212-9.

20. Hinkley $T$, Salmon J, Okely AD, Hesketh $\mathrm{K}$, Crawford D. Correlates of preschool children's physical activity. Am J Prev Med. 2012;43(2):159-67.

21. Cliff DP, Reilly JJ, Okely AD. Methodological considerations in using accelerometers to assess habitual physical activity in children aged 0-5 years. J Sci Med Sport. 2009;12(5):557-67.

22. Cliff DP, Okely AD, Smith LM, McKeen K. Relationships between fundamental movement skills and objectively measured physical activity in preschool children. Pediatr Exerc Sci. 2009;21(4):436-49.

23. Sirard JR, Trost SG, Pfeiffer KA, Dowda M, Pate RR. Calibration and evaluation of an objective measure of physical activity in preschool children. J Phys Act Health. 2005:2(3):345-57.

24. Hinkley T, O'Connell E, Okely AD, Crawford D, Hesketh K, Salmon J. Assessing volume of accelerometry data for reliability in preschool children. Med Sci Sports Exerc. 2012;44(12):2436-41.

25. Evenson KR, Catellier DJ, Gill K, Ondrak KS, McMurray RG. Calibration of two objective measures of physical activity for children. J Sports Sci. 2008;26(14):1557-65.

26. Willett W, Stampfer MJ. Total energy intake: implications for epidemiologic analyses. Am J Epidemiol. 1986;124(1):17-27

27. Owen N, Sugiyama T, Eakin EE, Gardiner PA, Tremblay MS, Sallis JF. Adults' sedentary behavior determinants and interventions. Am J Prev Med. 2011;41(2):189-96

28. Wake M, Salmon L, Waters E, Wright M, Hesketh K. Parent-reported health status of overweight and obese Australian primary school children: a cross-sectional population survey. Int J Obes Relat Metab Disord. 2002;26(5):717-24.

29. Australian Council for Health Physical Education and Recreation. Australian health and fitness survey 1985. Adelaide: ACHPER Publications; 1985.
30. Cole TJ, Bellizzi MC, Flegal KM, Dietz WH. 0045stablishing a standard definition for child overweight and obesity worldwide: international survey. BMJ. 2000;320(7244):1240-3.

31. Cole TJ, Flegal KM, Nicholls D, Jackson AA. Body mass index cut offs to define thinness in children and adolescents: international survey. BMJ. 2007;335(7612):194

32. World Health Organization. Obesity: Preventing and managing the global epidemic. Geneva: World Health Organization; 2000.

33. Hinkley T, Salmon J, Okely AD, Crawford D, Hesketh K. The HAPPY study: development and reliability of a parent survey to assess correlates of preschool children's physical activity. J Sci Med Sport. 2012;15(5):407-17.

34. Atkin AJ, Gorely T, Clemes SA, Yates T, Edwardson C, Brage S, et al. Methods of Measurement in epidemiology: sedentary Behaviour. Int J Epidemiol. 2012;41(5):1460-71.

35. Miller SA, Taveras EM, Rifas-Shiman SL, Gillman MW. Association between television viewing and poor diet quality in young children. Int J Pediatr Obes. 2008;3(3):168-76.

36. $\mathrm{Xu} \mathrm{H}$, Wen LM, Hardy LL, Rissel C. Associations of outdoor play and screen time with nocturnal sleep duration and pattern among young children. Acta Paediatr. 2016:105(3):297-303.

37. Jago R, Sebire SJ, Edwards MJ, Thompson JL. Parental TV viewing, parental self-efficacy, media equipment and TV viewing among preschool children. Eur J Pediatr. 2013;172(11):1543-5.

38. Christakis DA, Zimmerman FJ, DiGiuseppe DL, McCarty CA. Early television exposure and subsequent attentional problems in children. Pediatrics. 2004;113(4):708-13.

39. Carson V, Janssen I. Associations between factors within the home setting and screen time among children aged $0-5$ years: a cross-sectional study. BMC Public Health. 2012;12:539.

40. Smith BJ, Grunseit A, Hardy LL, King L, Wolfenden L, Milat A. Parental influences on child physical activity and screen viewing time: a population based study. BMC Public Health. 2010;10:593.

41. Kuepper-Nybelen J, Lamerz A, Bruning N, Hebebrand J, Herpertz-Dahlmann $\mathrm{B}$, Brenner $\mathrm{H}$. Major differences in prevalence of overweight according to nationality in preschool children living in Germany: determinants and public health implications. Arch Dis Child. 2005;90(4):359-63.

42. Spurrier NJ, Magarey AA, Golley R, Curnow F, Sawyer MG. Relationships between the home environment and physical activity and dietary patterns of preschool children: a cross-sectional study. Int J Behav Nutr Phys Act. 2008:5:31.

43. Barr-Anderson DJ, Fulkerson JA, Smyth M, Himes JH, Hannan PJ, Holy Rock $B$, et al. Associations of American Indian children's screen-time behavior with parental television behavior, parental perceptions of children's screen time, and media-related resources in the home. Prev Chronic Dis. 2011;8(5):A105.

44. Hoyos Cillero I, Jago R. Systematic review of correlates of screen-viewing among young children. Prev Med. 2010;51(1):3-10.

45. Taylor RW, Murdoch L, Carter P, Gerrard DF, Williams SM, Taylor BJ. Longitudinal study of physical activity and inactivity in preschoolers: the FLAME study. Med Sci Sports Exerc. 2009:41(1):96-102.

46. Montgomery C, Reilly JJ, Jackson DM, Kelly LA, Slater C, Paton JY, et al. Relation between physical activity and energy expenditure in a representative sample of young children. Am J Clin Nutr. 2004;80(3):591-6.

47. Pate RR, Mclver K, Dowda M, Brown WH, Addy C. Directly observed physical activity levels in preschool children. J Sch Health. 2008;78(8):438-44.

48. Cardon GM, De Bourdeaudhuij IM. Are preschool children active enough? Objectively measured physical activity levels. Res Q Exerc Sport. 2008;79(3):326-32

49. Temmel CSD, Rhodes R. Correlates of Sedentary Behaviour in Children and Adolescents Aged 7-18 Years: A Systematic Review. The Health \& Fitness Journal of Canada. 2013:6(1):119-99.

50. Australian Bureau of Statistics. Census of Population and Housing. Canberra: ABS; 2011. 